
Joan Petit

\title{
Marketing for the beginner Resources from the ACRL Library Marketing and Outreach Interest Group
}

A re you new to outreach work? Were you tasked with planning events highlighting your services, collections, or spaces and don't know where to start? Do you need to create promotional materials but have no background in design? Is there little to no budget? The administrators of ACRL's Library Marketing and Outreach Interest Group have put together a beginner's guide that includes groups to join, blogs and websites to read, free and low-cost graphic design tools, collections of free images and icons, and other online resources that spark inspiration when you have hit the proverbial creativity wall.

\section{Ideas and inspiration}

- 5 Minute Librarian. The 5 Minute Librarian blog is perfect for librarians who need timely marketing inspiration on the fly. From ready-to-go book displays, podcasts to follow, or top ways to advertise your library, 5 Minute Librarian has advice on everything from social media, marketing, technology, and book displays. There is also a special

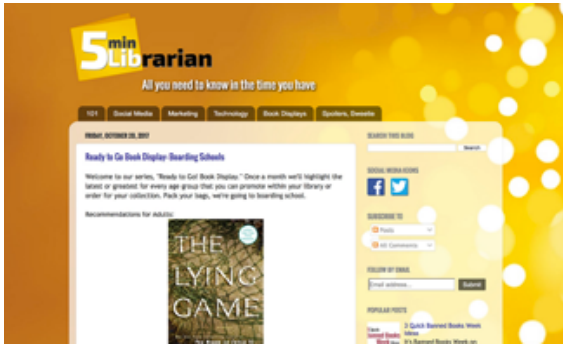

section called "Spoilers, Sweetie!" written by volunteer librarians who write the spoilers for award-winning books. Access: http:// www.5minlib.com/; https://www.facebook. $\mathrm{com} / 5$ minlib.

- ACRL Library Marketing and Outreach Interest Group (LMOIG). LMOIG is an ACRL interest group charged with providing a forum for discussing effective marketing and sharing information about the value of academic and research libraries, including services and events. The interest group currently holds an official membership of close to 1,000 and a lively Facebook page of more than 3,400 members. The Facebook group serves as the primary place for discussions between academic librarians and library staff, though the group is also open to librarians and library staff from other library types.

Lindsay Davis is instruction and outreach librarian at the University of California-Merced, email: Idavis23@ ucmerced.edu, Jen Park is assistant librarian for access and outreach services at Mount Saint Mary College, email: jen.park@msmc.edu, Sabine Dantus is outreach librarian at Lynn University, email: sdantus@lynn.edu, Chris Davidson is campus and community engagement librarian at Northwestern University, email:c-davidson@ northwestern.edu, Bonnie Cohen Lafazan is director of Woodbridge Campus Library at Berkeley College, email: bla@berkeleycollege.edu, and Joan Petit, is communications and outreach librarian at Portland State University, email: jpetit@pdx.edu

(c) 2017 Lindsay Davis, Jen Park, Sabine Dantus, Chris Davidson, Bonnie Cohen Lafazan, and Joan Petit 
Librarians share experiences, ideas, successes and failures, and also ask questions like, "What is your experience with liaising with nonacademic departments on campus?" "What button maker should I buy, and how do I convince my administration to pay for it?" and "What are you doing for Banned Books Week?" Access: www.ala.org/acrl/aboutacrl /directoryofleadership/interestgroups /acr-iglmo; https://www.facebook.com /groups/acrl.lmao/.

- ACRL University Libraries Section (ULS) Academic Outreach Committee (AOC). AOC is a ULS committee charged with developing and maintaining a community of practice to share information and foster best practices in campus outreach for academic libraries. The committee hosts online roundtable discussions throughout the year around specific topics, such as Planning and Managing the Outreach Calendar for the Year, Collaborating with Campus Partners on Outreach Activities, and Outreach to International Students. The roundtables are great places to share experiences and learn from others in a small group setting. Previous discussions are hosted on the committee's YouTube page. Access: www.ala.org/acrl/uls/acr-ulsao; https://www.youtube.com/channel /UCjxSyisSf1WgdclboIzfM7Q.

- ALA LLAMA Marketing and Communications Community of Practice. Formerly the LLAMA Public Relations and Marketing Section, this group pulls together people in marketing and communications from public, special, and academic libraries. Its committees run the John Cotton Dana Library Public Relations Award and the PR Xchange, which showcase the best public relations work done in libraries. The Flickr stream for the PR Xchange is a great place to see examples of excellent library marketing materials. Access: http://www.ala.org/llama /communities/marketing; https://www.flickr. com/photos/prxchange-awards/.

- Libraries Transform. The Libraries Transform campaign is designed to increase the awareness of the value, impact, and services of libraries and librarians and to elevate the critical role they play in the digital age. Materials include branded print and digital materials, from posters and postcards to bookmarks, as well as tips for adapting the campaign to individual libraries. Access: http://www.ala.org/advocacy/libraries -transform-campaign; http://www . ilovelibraries.org/librariestransform/.

- Programming Librarian. Programming Librarian, run by the ALA Public Programs Office, serves as a place to inspire other librarians interested in developing programming through resources, ideas, and professional development opportunities. The website offers detailed program models browsable by the type of library, topic, and projected budget. Blog posts offer further experiences, tools, and tips. The Programming Librarian Facebook group offers librarians more dynamic interactions with each other, including a space to quickly share their experiences or ask questions. Access: http://www.programminglibrarian. org/; https://www.facebook.com/groups /ProgrammingLibrarianInterestGroup/.

- WebJunction. WebJunction, a program of OCLC Research, helps librarians and library staff from all types of libraries learn from peers through free webinars, which are recorded and archived; online classes and other training opportunities; as well as featuring news and documents. Topic areas include marketing, outreach, programming, advocacy, and more. Access: http://www. webjunction.org/.

\section{Graphic design inspiration and tools}

- Ad/Lib. Ad/Lib shares examples of good design and advertising work from libraries of all types. Featuring websites,

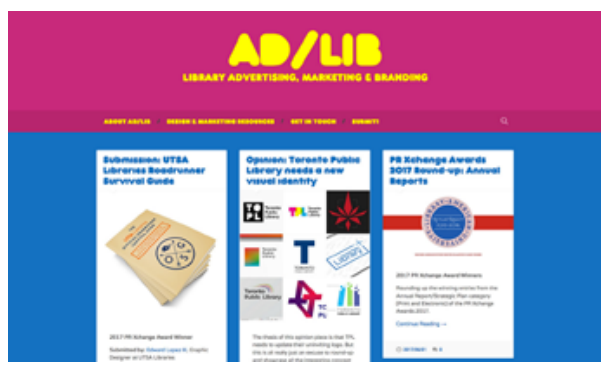


marketing campaigns, logos, branding, signage, flyers, etc., Ad/Lib shares both readersubmitted designs and information found online. Readers can browse content by format (print, digital, multimedia, etc.), library type (public, academic, and special), and post type (branding, wayfinding, web redesign, etc.). Access: http://adlib.info/.

- Adobe Spark. Adobe Spark, which includes Spark Post, Page, and Video, is an online graphic design tool and app that can help those with little-to-no design experience create professional-looking content for social media or websites. Spark Post helps users design posts, thumbnails, advertisements, and covers for social media. Spark Page allows users to create magazine-style webpages. Spark Video allows users to record narration, add text, upload photos, or search through Creative Commons-licensed photos and icons to add visual elements to videos. Although there is no cost to use the basic Adobe Spark, for a small monthly fee, users can replace the Adobe Spark logo with their library logo and select branded colors, fonts, themes, and templates. Access: http:// spark.adobe.com.

- Canva. Canva is an online graphic design tool that allows users to create Facebook posts, blogs, posters, flyers, and all kind of the promotional material they may need to design. Users can browse through free and low-cost pre-created templates or create designs from scratch. While some icons, images, and templates do have a small fee, users may also upload their own images. Canva's free tutorials are a great way for people with no background in design to learn how to make appealing materials step by step. Nonprofits can apply for a free subscription to more tools, including custom fonts and branding tools. Access: www.canva.com.

- Librarian Design Share. Librarian Design Share features examples of reader submitted design work, including flyers, displays, handouts, websites, and more, from libraries of all types. Readers can browse by design software (Adobe InDesign, GIMP, Google Slides, etc.) or by design type
(Instructional Materials, Logos, Slideshow Templates, etc.) All work published on Librarian Design Share is covered on a Creative Commons Attribution-NonCommerical ShareAlike 3.0 Unported license. Access: https:// librariandesignshare.org/.

- Piktochart. Piktochart is the leading online design tool to create promotional materials that best showcase information by way of infographics. While there is no cost to get started, paying a monthly fee allows users to create personalized color schemes, upload photos, and access hundreds of templates. While it does take some time to grasp the settings, Piktochart offers tutorials, and the Piktochart team is also available to help. Access: www.piktochart.com.

- Smore. Smore is an online design tool to easily create web-based flyers and newsletters that can be shared via email group lists, a link, or directly to social media, including Facebook and Twitter. Users also have access to analytics that can help measure the reach of each flyer or newsletter. With the free version of Smore, users can create up to three newsletters using basic templates. There are a variety of subscriptions (personal, business, corporate, and educator) that can be purchased for a small monthly or annual fee. The fee-based accounts allow users to create an unlimited number of flyers/newsletters using customizable backgrounds. Access: https://www.smore.com.

\section{Icons and images}

- CC Search. CC Search provides users with the ability to search for content with Creative Commons licenses from a variety of databases offered by independent organizations, including Wikimedia Commons, SoundCloud, Pixabay, Google Images, etc. Users can also limit results to content that can be used for commercial purposes and/ or modified, adapted, or built upon. As Creative Commons does not have control over search results, users should doublecheck to see that the content is under a CC license by following the links. The new Beta CC Search, with new search filters and 
one-click attribution, allows users to search across a variety of vetted open-sourced content through one single interface. Access: https://search.creativecommons. org/; Beta Version Access: https://ccsearch. creativecommons.org/.

- Flaticon. Flaticon features more than 573,000 free vector icons that can be used for personal and commercial purposes. Premium subscribers who pay a small monthly fee also have access to premium icons and don't need to provide attribution. Users who aren't premium subscribers must provide credit to the icon designer. Users can search and download individual icons or icon packs that are organized by category (finance, technology, etc.). Icons are available in PNG, SVG, EPS, PSD, and BASE 64 formats. Flaticon's @ font-face Generator allows users to convert icons to webfonts. Flaticon also has an Adobe extension and Mac OS X app. Access: https:// www.flaticon.com/.

- IconArchive. IconArchive has a library of more than 500,000 icons organized in 45 different categories. Users can search or browse for individual icons or icons sets that can be sorted by alphabet, popularity, number of icons, resolution (the highest resolution, $1024 \mathrm{px}$, is listed first), color, size, or artist. Icons can be downloaded in a variety of sizes and formats. The license and attribution information is also available for each icon and icon set. Access: http://www. iconarchive.com/.

- Pexels. Pexels is a library of 40,000 free high-quality stock photos, which can be used for both personal and commercial purposes. All photos are covered under the Creative Commons Zero license, and attribution is not required. Users can search for images or can also browse by color, popular photos, popular searches, photographers, and categories (summer, abstract, city, fashion, etc.) Every image can be downloaded in a variety of sizes, and each photo also has suggestions for similar images. Those who sign up for accounts receive 40 additional photos to download and can upload their own photos to the Pexels community. Access: https:// www.pexels.com/.

- Pixabay. Pixabay features more than 1.1 million photos, vector graphics, illustrations, and videos that can be used for commercial and noncommercial purposes. All content is licensed under Creative Commons. Users can search by media type, orientation, pixel size, color, and categories ranging from animals, architecture, religion, music, beauty/fashion, and people. Images can be downloaded in a variety of sizes, and each image also provides users with suggestions for similar images. Access: https:// pixabay.com/.

- Unsplash. Unsplash is a searchable library of free high-resolution digital photographs that can be downloaded and used for any purpose, both commercial and noncommercial. In addition to searching for images, users can also browse the most popular collections by topic or the results of trending searches. Unsplash also has a Chrome extension, so each new tab provides a new photograph, which can also be downloaded. Users who create accounts can make private or public collections and receive announcements, recommended photos, resources, tips, etc. Access: https:// unsplash.com/.

\section{Other resources}

- ACRL Library Marketing and Outreach Libguide. The ACRL Library Marketing and Outreach LibGuide, a project of the Library Marketing and Outreach Interest Group, is a growing resource that includes the resources listed above and more. The guide features groups to join; conferences to attend; books, blogs and websites to read; sample marketing plans; resources for social media; and more tools for graphic design work and collections of images and icons. A go-to resource for anyone involved with library marketing and outreach, be sure to bookmark the guide and check in frequently for updated content. Access: https://acrl.libguides.com /marketingresources. $\neq 2$ 